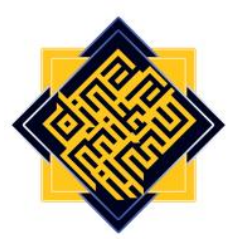

\title{
Exploring Muslim Pre-Service Teachers' Honesty on Cheating and Plagiarism: A Survey in Indonesian Islamic University
}

\author{
Rafika Rabba Farah \\ Universitas Muhammadiyah Malang \\ e-mail: rafikafarah@gmail.com
}

\begin{abstract}
Cheating and plagiarism have been crucial issues among students studying either at high school or undergraduate levels. This present study aims to reveal the cheating and plagiarism practices among pre-service teachers in their undergraduate program at one Islamic university in Indonesia. As Muslim teacher candidates, the respondents are urged to uphold academic integrity and honesty. Thus, this study seeks to provide data on how serious the academic ethics immersed in Muslim pre-service teachers. The method implemented for this study was a cross-sectional survey. The respondents were students enrolled in the Faculty of Education, which comprises several departments in the education fields. Results indicate that respondents were recorded as having morally ethical on one aspect of academic integrities, 95\% never paid someone else for the exam, 75\% never changed answers after the marking process, and 50\% declared rarely copy an answer. Yet, there was also a display of less ethical attitude on some other academic behaviors driven by cultural factors. Thus, some teaching implications are highlighted for teachers and students to combat cheating and plagiarism practices among pre-service teachers in Indonesian Islamic universities.
\end{abstract}

Keywords: Cheating, plagiarism, academic ethics, pre-service teachers 


\section{Rafika Rabba Farah}

\section{A. Introduction}

As Muslims, pre-service teachers are bound to uphold the Muslim traits that have been taught in their religion, mainly being honest in every condition he/she is. Academic integrity is one of the indicators that a Muslim can be defined as a good Muslim. However, cheating and plagiarism have been serious issues for higher education institutions across the globe. Some literature highlight that there are three main factors contributing to this issue which are related to the cultural context, institutional context, and individual choice (Hughes \& McCabe, 2006). In measuring the impact between culture and unethical conduct, research finding shows that individualist (Caucasians) has more tendency to plagiarism practices compared to the collectivists (Asians) (Martin, 2012). Furthermore, culture is also captured as a contributing factor to plagiarism that students perceive more on cultural definition to gain personal success and also to gain race or group power (Heckler \& Forde, 2015). In that research, a student reveals that it is culturally legitimate to cheat in gaining personal success and that a student feels inferior if he/she is assumed as 'dumb'; thus, plagiarism is the instant way to do it.

Responding to such issues, research on academic integrity has been widely explored worldwide. A study on students of Computer Sciences in King Saud University found that cheating and plagiarism are common among them. Meanwhile, they believe that such practices are unethical and against religious norms (Hosny \& Fatima, 2014). In a similar vein, factors that trigger higher education students in Canada to do academic misconduct are student maturity, students' own definition of academic misconduct, poor understanding of policies and procedures, and a lack of knowledge on academic misconduct (Hughes \& McCabe, 2006). Similarly, pre-service teachers in Turkey are found to have a tendency to commit internet plagiarism that has time constraints, workload, and assignment level of difficulty become the key reasons to this tendency (Eret \& Ok, 2014).

In the view of the previously mentioned research findings, the research settings are mainly conducted in developed countries where technology and tool are applied in the academic system. However, there are still fairly limited studies exploring on Muslim preservice teachers' honesty a higher education context in developing country like Indonesia. Hence, researching Muslim pre-service teachers' academic honesty is significant to measure as they, later in their future profession, will teach students and disseminate the knowledge of academic ethics. Therefore, this present research aims to discover preservice teachers' academic honesty in their bachelor program, particularly on cheating and plagiarism practices. Thus, the result of this current research is projected as input for higher education management to take the issue of cheating and plagiarism into a serious account that such misconduct can be better prevented.

\section{B. Research Methodology}

The method implemented in this present study was a mixed method. The statistical data were administered through a close-ended questionnaire adapted from Hosny \& Fatima (2014). It was distributed to 127 Muslim respondents enrolling in one Islamic Private University through an online survey platform, Google form. The questionnaire was 
distributed to the respondents during the final test period where they joined the on-site exam and in the midst of finalizing their paper projects. Thus, they were immersed in answering the survey questions. Using cross sectional survey, the quantitative data were analyzed using simple statistical analysis. Later, respondents' answer-qualitative datawas verified through respondents' reflective writing. The respondents of this study were students enrolling in the Faculty of Education at Universitas Muhammadiyah Malang in Indonesia.

\section{Findings}

\section{Respondents' Demographic Profile}

The total respondents were 127 Muslim pre-service teachers enrolling in the disciplines of the Faculty of Education.

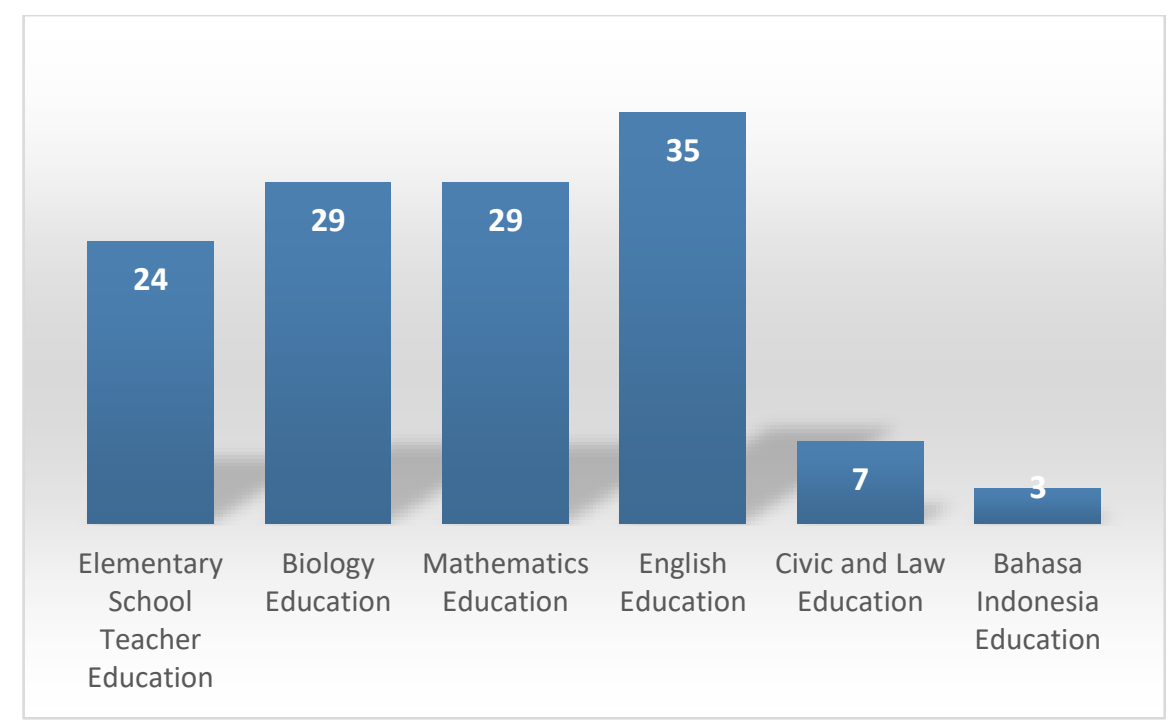

\section{Frequency of some cheating practices}

Data presents clearly that there is a significant portion, for $95 \%$, that pre-service teachers never paid someone else to do an assignment. Also, it is recorded that pre-service teachers never change an answer after the grading process is done for a considerable amount, for $75 \%$, and rarely copy from another student (50\%). Pre-service teachers further justify that they sometimes being pressured by classmates to give the answer (48\%) and frequently commit cheating practice in the form of extracting hints from the instructor (40\%). 


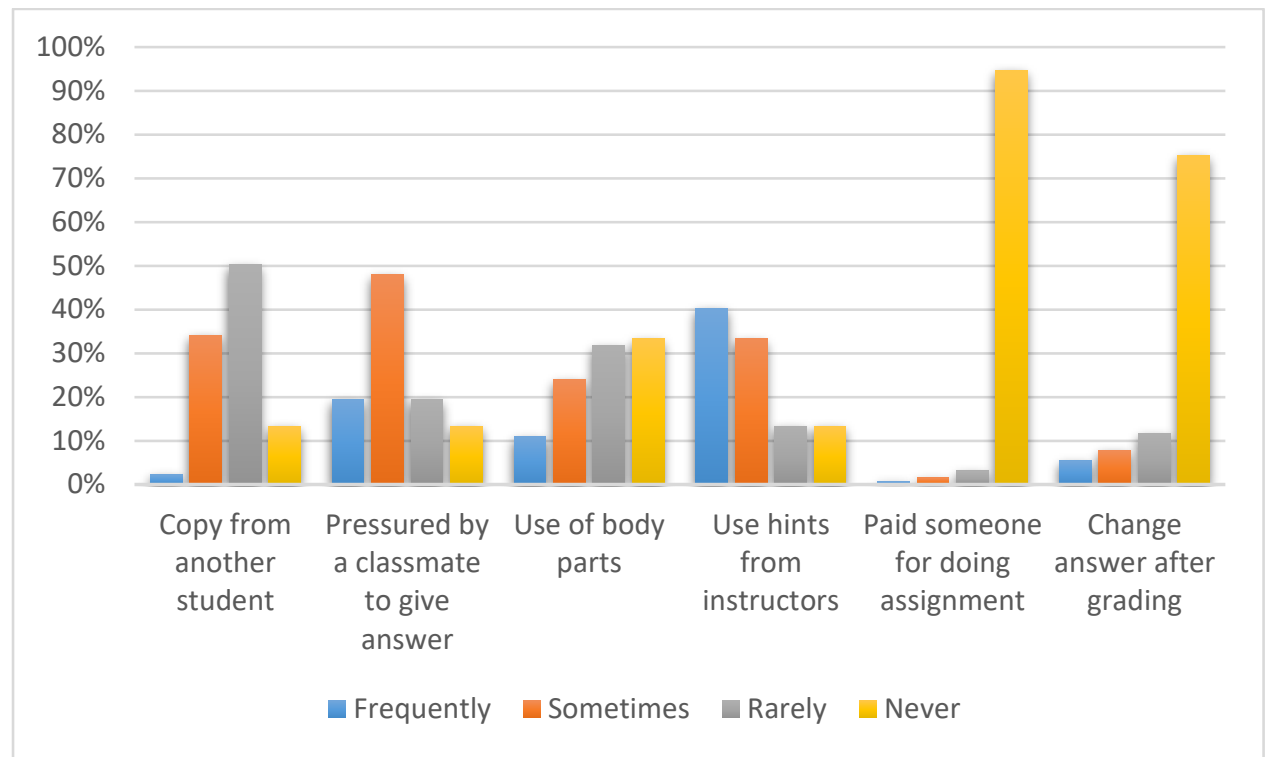

Figure 1. Frequency on cheating practices

One of the frequency indicators for pre-service teachers to cheat during the exam was the force of classmates. A participant of the study admitted that she experienced once that she did not give her friends the answer; they will gossip about her in a way. This condition, she claimed as a dilemma. Further, she narrated as follows.

At that time, I was still in the first semester, ... In the middle of the quiz, my friend next to me called me asking to see the results of my answers. Firstly, I was afraid to tell them and afraid of being scolded by the lecturer. But, I also pity if he was not given a cheat sheet, pity if he could not answer that question. So, I ventured to give a cheat sheet to my friends. Then not long after, the lecturer looked at us. Then, my answer sheet and my friends were scribbled by the lecturer and finally were scolded. After that, the lecturer said that our quiz score was deducted for 25 points. Being published, I knew that my actual score was 95 but deducted, so it was only 75 . I feel sad about that because some friends underestimate me, so did my lecturer. However, I was still grateful that my score was above the average score. (RWR1-P2)

Likewise, a participant had also experienced being requested by her friends to write a report. It was also uneasy for her to refuse the request. This situation is stated below. One time, a freshman asked me for (Internship) I report because she was too lazy to write her own report. Eventually, she changed just the data of the school they went to. As a reward, this student bought me a meal as a thank you gift. Also, a friend of mine from another university did the same thing because we are in the same major. (RWR1-P4) 
The next participant refers back to her high school experience. She used body parts a lot during national exams as it was considered a high-stake test for its result will determine her university life. She describes it as follows.

The use of body parts, I think this is the easiest way of cheating. Moreover, if it is a multiple-choice test. Again, I used it a lot in my school era honestly. I used to give my answer to my friends using body gestures. Occasionally, I also used hints from an instructor. I think it was common in the school environment to give students hints or even the answer during the national examination. The school itself did cheating in order to ensure that every student will pass the national examination and graduate from the school. (RWR1-P1)

\section{Reasons for cheating practices}

The figure shows that the major reasons for pre-service teachers to commit cheating were because of the difficulty of an exam (42\%), helping a friend (37\%), the importance of grade $(33 \%)$, and lack of time to study $(31 \%)$.

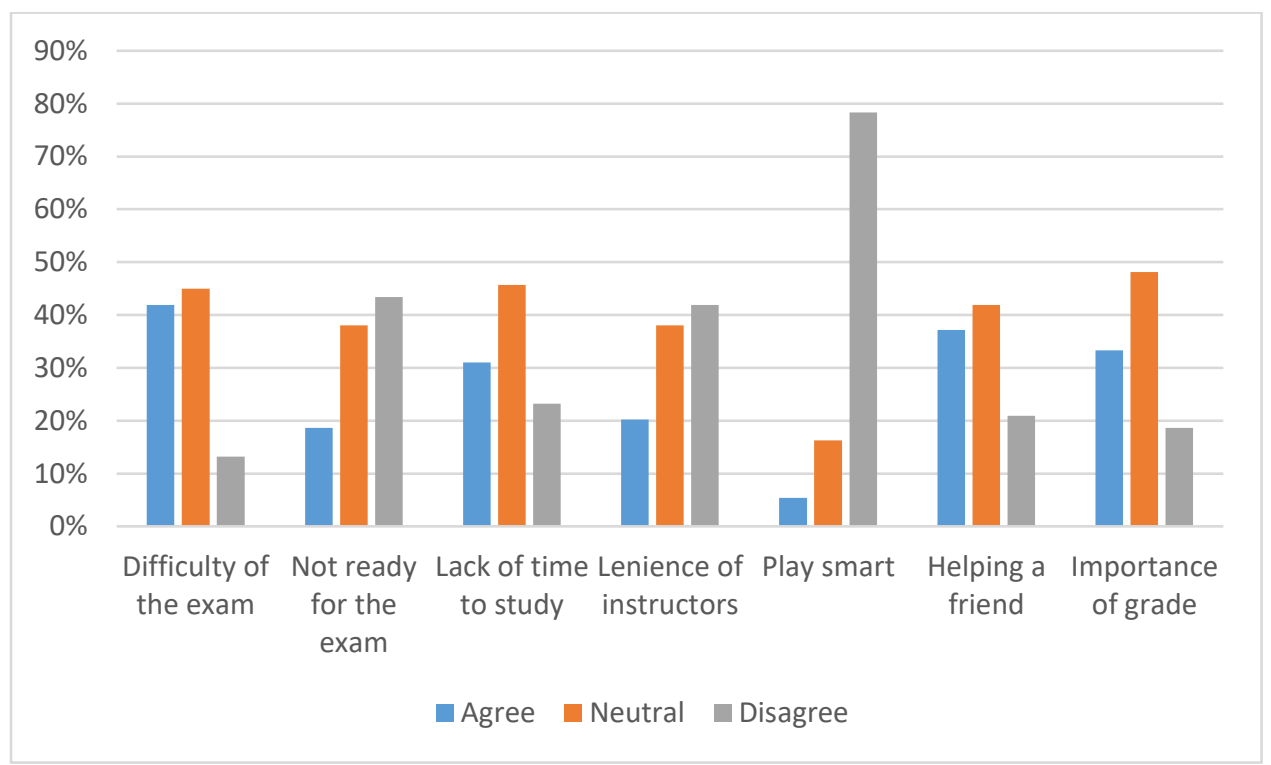

Figure 2. Reasons for cheating practices

The difficulty of the exam is a significant contributing factor for students to cheat. One participant expresses her experience as follows.

The difficulty of the exam is when the lecturer gives us an irrelevant topic for the exam that we do not know, and he/she told us that we had discussed it during the class session. (RWR2-P4)

Another important reason is how students value the importance of grades for their future academic endeavours. 


\section{Rafika Rabba Farah}

The importance of grades is one of my reasons why I did this because many future opportunities require conditions with satisfactory grades such as work, scholarship tests, and so on. Sometimes, I think that even at school, we have already known something about cheating and corruption. So, how can we later go to the workforce if our grades are not satisfactory!? Maybe some people will underestimate these two things. (RWR2-P3) (Venna Bella)

\section{Knowledge about Plagiarism}

The chart has clearly shown that pre-service teachers' cognitive skill on plagiarism is very distinctive as major population understands that plagiarism means replacing words without citing and using other author's exact words, for around 90\%. On the topic of plagiarism means submitting another person's work is recorded to have a variety of distribution, for $55 \%$ yes, $26 \%$ no, and $19 \%$ uncertain.

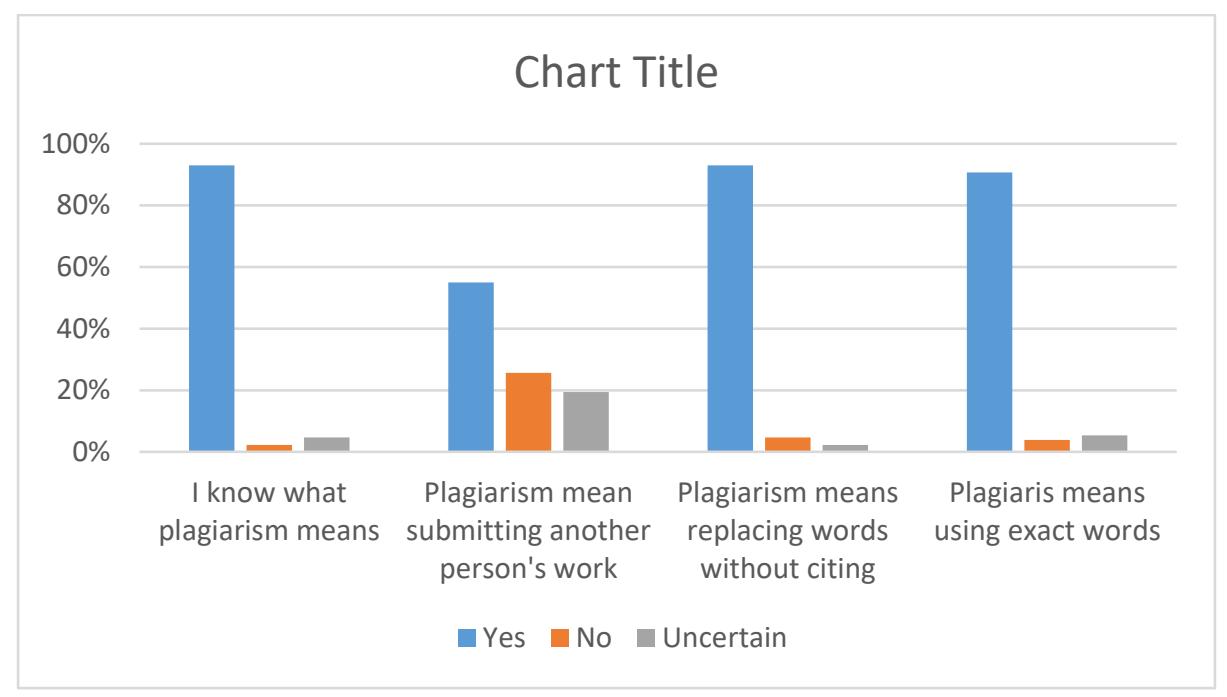

Figure 3. Knowledge about Plagiarism

\section{Sources of plagiarism}

On where pre-service teachers commit plagiarism, data presents that electronic sources have the most significant source. Pre-service teachers frequently used the electronic source for $42 \%$ than the printed version for only $22 \%$. Another source that the respondents frequently used is the idea of others. 
Exploring Muslim Pre-Service Teachers' Honesty on Cheating and Plagiarism

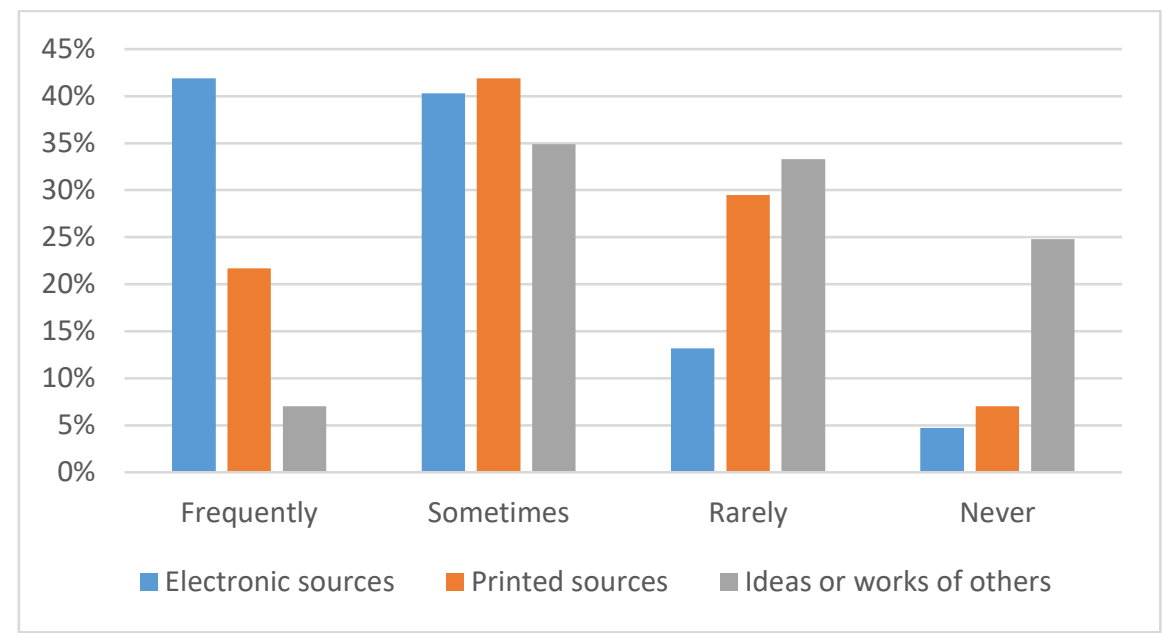

Figure 4. Sources of plagiarism

There are two main sources for students to plagiarize; first one is an online source and the second is printed one. Below is how one participant describing her experience using an online one.

I use electronic sources as my plagiarism sources. Actually, I am not sure whether I am doing plagiarism or not because whenever I try to paraphrase a sentence, it is just going to be the same as the original source. So, I guess it is still called as plagiarism. The idea to differentiate between summarizing, paraphrasing, and citing is still my concern. It might be because I do not know much about them, rarely practice and too lazy to read. So, in the very beginning of college life, I still do plagiarism and use an online or electronic source of plagiarism since it is going to be easier for me to instantly take and put all the words, I might need into my draft rather than from the printed sources. Using the printed sources is way more difficult because I have to rewrite or retype all the words into the laptop. (RWR3-P1)

Meanwhile, another participant preferred to use the textbook as a source to do plagiarism. It is stated as follows.

Not only electronic sources, sometimes I also use printed sources to plagiarize. It is to find reliable sources in supporting the statements that I wrote in the paper that I made. Sometimes electronic sources are incomplete, unlike print sources... Not only that, electronic sources are also a bit complicated. Sometimes, if I want to download a good journal file, I have to pay first or create an account. Creating an account to download a journal is not as easy as creating an account on social media. (RWR3-P2)

Data shows clear evidence that the participants of the study are found to have a high dedication towards honesty. However, nearly half of them are forced to commit cheating 


\section{Rafika Rabba Farah}

because of friendship. Further, on their reasons for cheating during the exam, it is highlighted that helping friends during the exam was the second highest. It can be analyzed that cheating practice among university students has an indication to deal with the cultural issue. Also, the phenomena have been narrated in the reflective writing results revealing that the participants are feeling uneasy, being gossiped, and perceived cheating during the exam is a common trait to do between friends at the school. This situation is also supported by data that the participants consider the importance of getting a good grade highly. To conclude, attaining a good grade becomes the driving force for all phenomena discussed in the paper. Meanwhile, for the plagiarism issue, participants acknowledging themselves as being knowledgeable on what plagiarism is. However, this acknowledgment is not a guarantee that the participants are aware of what they are doing is considered plagiarism. Thus, it can be said that the theory they know about plagiarism does not meet the practice for some internal reasons, such as the idea of finishing the task instantly and being lazy.

\section{Discussion}

The major finding of this research unveils that teacher-candidate respondents are recorded positive in one aspect of academic integrity, such as $95 \%$ of them documented never paid someone else for the exam; 75\% never changed answers after marking process, and 50\% declared rarely copy the answer from another. However, in another aspect, the respondents sometimes pressured to cheat during examination because there was pressure from classmates, accounted for $48 \%$. Furthermore, it is listed in the reasons for respondents' agreement to cheating practices are because they want to help their classmates for $37 \%$; also consider that getting high grades is important (33\%). Below is a discussion on why it is all happens and how to better combat the aforementioned academic behavior is described.

The finding of the study revealed the globalization has brought many students severe pressure on their study load. The orientation of enrolling into higher education is supposed to create someone to be knowledgeable, to be morally mature, and to be skillul has now transformed into a more job-oriented year of study. Thus, one of the major reasons why to cheat was the consideration of the importance of grades. This was further confirmed by one participant that high grade was significant for her better future opportunities, i.e. competing in the workforce and scholarship application. This finding inveterate the study of Bachore (2016) asserting that cheating practice is done to get extra points to raise students' current grades; afraid of getting a low score, the unfair judgment of teachers, and temptation on choosing a short-cut way (Özbek \& Çeyiz, 2017); also, there is a high pressure from parents for male students to receive good GPA (Quraishi \& Aziz, 2017). Again, a high GPA is highly valued to get a promising job in students' context.

Analysing the prevalent of academic dishonesty among students, there are several contributing factors to this, as it is supported by Balbuena \& Lamela (2015), who argue that the reasons lie in the burden of curriculum policy, student and teacher incompetence, and study environment. Further, the phenomena are confirmed by the study done by 
Jamaluddin et al. (2021), revealing that in a collectivistic society, cheating practice is triggered by collaboration rather than competition. The finding further suggests that cheating practice is potentially driven by culture. As the phenomena captured from one of the participants (participant 1) declares that cheating has been common in the school as it was perceived as ordinary practices to ensure every student passes the high-stake exam. This saying indicates that cheating practice is also bound to the educational cultural system. Therefore, it is also valuable to know whether the practices students do are related to how they perceive cheating as part of the dominant culture in the society or the current campus they go. However, another study conducted by Zhang \& Yin (2020) disconfirmed the cultural effect of cheating. The study discovered that peer influence is the determinant factor for collaborative cheating, not cultural dimensions. It is further argued that the significant contributing factor does not lay on individualism or collectivism culture, but more on friendship circle.

To resolve the tension on cheating practice, an interesting research finding indicates that altering students' seating arrangement can be effective in minimizing cheating during the exam (Topîrceanu, 2017). Using social network analysis, this study highlights the importance of considering students' friendship circle, thus breaking up their non-befriend to sit next to each other during the exam is prevalent. Further, it is suggested that higher education management should set a topology layout for students' seating arrangement. As for plagiarism, many research findings suggest that higher education use academic software tool as a way for prevention (Do Ba et al., 2017; Torres-Diaz, Duart, \& HinojosaBecerra, 2018); Cronan, McHaney, Douglas, \& Mullins, 2017). To make the argument stronger, it was revealed that western students are indicated to do more plagiarism than the eastern counterpart just because western universities have the software tool for plagiarism detector (Foltýnek \& Glendinning, 2015). Another finding suggests that plagiarism is found more widespread in the university not applying Turnitin than the ones applying it (Tran, Huynh, \& Nguyen, 2018).

The result of this research has contributed to the field of education, in particular, in its management system to uphold academic integrity. This study has focused on capturing the cheating and plagiarism issue which its tendency needs to be cut off. Thus, this study suggests that academic tools or the use of technology can be a way for educators to welcome a new era of the higher education management system, aiming that cheating and plagiarism become no more issues for every pre-service teacher. Doing such effort, the Indonesian education system will be improved, and the quality of teacher graduates can be assured.

Not to mention that sometimes, someone become more pious because of system, in this case, academic behavior is ruled by software tool, than believing to religious norms. It is factual that a study demonstrates there is no direct and indirect correlation between religiosity variables, namely belief, and behavior, on cheating behavior; yet, students' religious capacity that leads to their perception can be a determinant for their cheating behavior (Hadjar, 2017). However, based on the setting that the respondents of the present study are in a religious context-Indonesia-religiosity should actually build 


\section{Rafika Rabba Farah}

students' behavior on cheating practices. How good the tool mentioned to curb the plagiarism issue, religious norms, and morality are the actual important components of all. Students' self-awareness is resulted from within themselves, not made up. True education is to make a human more humane.

\section{E. Conclusion}

This present study concludes that Muslim pre-service teachers were recorded to uphold the academic integrity behavior in certain aspects, for example, never paid someone for the exam, never change answers after being marked, and never copy answers form another friend. However, they are documented to fail to maintain some other aspects of academic integrity, as previously discussed. With this, the university must address such issues of combating dishonest behavior among students, mainly focusing on technology use and students' integrity improvement during their four-year study. If failing to uphold academic integrity, Muslim pre-service teachers are likely also to fail to educate the whole nation.

\section{BIBLIOGRAPHY}

Bachore, M. M. (2016). The nature, causes and practices of academic dishonesty/cheating in Higher Education: The case of Hawassa University. Journal of Education and Practice, 7(19), 14-20. Retrieved from https://files.eric.ed.gov/fulltext/EJ1109249.pdf

Balbuena, S. E., \& Lamela, R. A. (2015). Prevalence, Motives, and Views of Academic Dishonesty in Higher Education. Asia Pacific Journal of Multidisciplinary Research, 3(2), 69-75.

Cronan, T. P., McHaney, R., Douglas, D. E., \& Mullins, J. K. (2017). Changing the Academic Integrity Climate on Campus Using a Technology-Based Intervention. Ethics and Behavior, 27(2), 89-105. https://doi.org/10.1080/10508422.2016.1161514

Do Ba, K., Do Ba, K., Lam, Q. D., Le, D. T. B. A., Nguyen, P. L., Nguyen, P. Q., \& Pham, Q. L. (2017). Student plagiarism in higher education in Vietnam: an empirical study. Higher Education Research and Development, 36(5), 934-946. https://doi.org/10.1080/07294360.2016.1263829

Eret, E., \& Ok, A. (2014). Internet plagiarism in higher education: tendencies, triggering factors and reasons among teacher candidates. Assessment and Evaluation in Higher Education, 39(8), 1002-1016. https://doi.org/10.1080/02602938.2014.880776

Foltýnek, T., \& Glendinning, I. (2015). Impact of policies for plagiarism in higher education across Europe: Results of the project. Acta Universitatis Agriculturae et Silviculturae Mendelianae Brunensis, 63(1), 207-216. https://doi.org/10.11118/actaun201563010207

Hadjar, I. (2017). The Effect of Religiosity and Perception on Academic Cheating among Muslim Students in Indonesia. Journal of Education and Human Development, 6(1). https://doi.org/10.15640/jehd.v6n2a15

Heckler, N. C., \& Forde, D. R. (2015). The Role of Cultural Values in Plagiarism in Higher Education. Journal of Academic Ethics, 13(1), 61-75. https://doi.org/10.1007/s10805- 
014-9221-3

Hosny, M., \& Fatima, S. (2014). Attitudes of Students Towards Cheating and Plagiarism: University Case Study.pdf. Journal of Applied Sciences, 14(8), 748-757.

Hughes, J. M. C., \& McCabe, D. L. (2006). Academic Misconduct within Higher Education in Canada. Canadian Journal of Higher Education, 36(2), 1-21.

Jamaluddin, S. F., Adi, S. P., \& Lufityanto, G. (2021). Social influences on cheating in collectivistic culture: Collaboration but not competition. Group Dynamics: Theory, Research, and Practice, 25(2), 174-189. https://doi.org/10.1037/gdnoo00122

Martin, D. E. (2012). Culture and unethical conduct: Understanding the impact of individualism and collectivism on actual plagiarism. Management Learning, 43(3), 261273. https://doi.org/10.1177/1350507611428119

Özbek, O., \& Çeyiz, S. (2017). European Journal of Education Studies University Students ' Opinions On. European Journal of Education Studies, 3(8), 323-335. https://doi.org/10.5281/zenodo.832326

Quraishi, U., \& Aziz, F. (2017). Academic Dishonesty at the Higher Education Level in. Journal of Research and Reflections in Education, 11(1), 68-85. Retrieved from http://www.ve.edu.pk/jrre

Topîrceanu, A. (2017). Breaking up friendships in exams: A case study for minimizing student cheating in higher education using social network analysis. Computers and Education, 115, 171-187. https://doi.org/10.1016/j.compedu.2017.08.008

Torres-Diaz, J. C., Duart, J. M., \& Hinojosa-Becerra, M. (2018). Plagiarism, internet and academic success at the university. Journal of New Approaches in Educational Research, 7(2), 98-104. https://doi.org/10.7821/naer.2018.7.324

Tran, U. T., Huynh, T., \& Nguyen, H. T. T. (2018). Academic Integrity in Higher Education: The Case of Plagiarism of Graduation Reports by Undergraduate Seniors in Vietnam. Journal of Academic Ethics, 16(1), 61-69. https://doi.org/10.1007/s10805-017-9279-9

Zhang, Y., \& Yin, H. (2020). Collaborative Cheating among Chinese College Students: The Effects of Peer Influence and Individualism-Collectivism Orientations, Assessment \& Evaluation in Higher Education, 45:1, 54-69, doi: 10.1080/02602938.2019.1608504 